\title{
INORGANIC POLYMERS
}

\begin{abstract}
THE international symposium on "Inorganic Polymers", held at the University of Nottingham during July 18-21, attracted more than four hundred people, drawn from eighteen different countries. This response reflected the widespread interest in a subject virtually unmentioned a few years ago.

Contributions to the symposium were of two kinds : nine invited speakers gave full-length lectures, the texts of which are to be published by the Chemical Society; thirty-one shorter communications were presented and very briefly discussed. The most effective discussions were those which were held informally between sessions: these were facilitated by the fact that nearly all those attending were accommodated on the University campus. These social arrangements were excellent, and contributed in no small measure to the undoubted success of the meeting.
\end{abstract}

After the president of the Chemical Society (Sir Alexander Todd) had welcomed visitors in English, French, German and Russian, an introductory address was delivered by Dr. J. S. Anderson (National Chemical Laboratory). A main theme of this address was the problem, very fundamental to the symposium: "What is an Inorganic Polymer?" The theme recurred from time to time, and led to goodhumoured exchanges suggesting rivalry between organic and inorganic chemists over polymers which might be described as organo-metallic, metalloorganic, or inorganic. Anderson pointed out that there are really two parts to this problem: $(a)$ How large must the molecule be to be described as a polymer ? (b) What restrictions of chemical composition are implied by the adjective 'inorganic'? On the first point, cyclic structures such as $\left(\mathrm{PNCl}_{2}\right)_{\text {s }}$ occupied a prominent place in the discussions but are neither more nor less polymeric than, say, benzene. The second point is best dealt with by listing some of the types of nolymer which were discussed during the meeting. They fall naturally into three classes: (1) polymers containing no carbon, for example, the chain forms of sulphur and selenium, $\left(\mathrm{PNCl}_{2}\right)_{n}$, polyphosphates; (2) chain polymers in which the main chain does not involve carbon, for example, the siloxanes ( $\left.\mathrm{Si} R_{2}-\mathrm{O}-\right)_{n}$, where $R$ is organic; (3) chain polymers in which carbon forms only a part of the main chain, for example, co-ordination polymers of the type $(-M-R-)_{n}$, where $M$ is a metal and $R$ an organic unit. The best compromise definition might insist on the absence of carbon from the main chain, and then include (2) but not (3). In point of fact, the wide range of materials surveyed by different speakers reflects the origin of much of the recent work in this field in a search for polymers capable of practical use at high temperatures. Since the object is to improve on the performance of organic polymers, large organic groups have been automatically excluded from consideration.

Before reporting on papers which dealt with specific polymers, one other general lecture may be mentioned. Prof. G. Ge日 (Manchester) directed attention to the large number of the systems under discussion which could exist in either chain or cyclic forms, the latter containing usually 6 or 8 atoms in the ring. He outlined a thermodynamic analysis of the equilibrium between ring and chain forms, pointing out that both heat and entropy of conversion ring/ chain were likely to be small. In consequence, the equilibrium is readily displaced in either direction by small influences, and four classes of behaviour are possible: (i) chains unstable at any temperature; (ii), (iii) chains unstable below a 'floor temperature' or above a 'ceiling temperature'; (iv) an equilibrium chain concentration on any temperature. This analysis cannot yet be widely applied, due to lack of thermochemical data. In most of the systems described, equilibrium is not readily attained, and the product found in given circumstances is determ. ined by kinetic factors.

One of the classical problems of inorganic chemistry is that of the structure of the many phosphates which have been described. A review of recent work in this field, given by Prof. E. Thilo (Berlin), showed that much confusion had been resolved by recognizing the existence of ring and chain forms, for example:

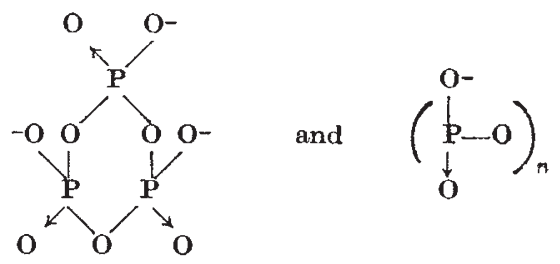

where $n$ could reach values as high as $10^{8}$. The chain forms may be either amorphous and soluble in water or crystalline and insoluble. The nature of the cation is of importance, in controlling the configuration of the chain and the crystal structure. The arsenates form a similar family, and mixed compounds, both cyclic and chain, can also be made.

Among the very few synthetic inorganic polymers which have already achieved industrial success the siloxanes occupy a prominent place. There have also been many attempts to modify the siloxanes by partial or complete replacement of silicon by other atoms. The lecture given by Prof. K. A. Andrianov (Moscow), who has been outstanding in this work, summarized some of his methods and results. Cyclic siloxanes such as $\left(\mathrm{SiMe}_{2} \mathrm{O}\right)_{4}$ are very well known, and Andrianov has described three-dimensional closed structures, including one which may be written as a cube having as its side:<smiles>C[AsH3]O[SiH]1O[SiH](C)O[SiH](C)O[SiH](C)O1</smiles>

Cyclic structures are readily opened by strong bases to give linear chains with terminal $-\mathrm{O}^{-}$. Reaction of such a chain with an alkoxide of aluminium, titanium or boron is reported to lead to polycondensation, for example:

$$
\mathrm{HO}-\left(\mathrm{Si}_{2} \mathrm{O}\right)_{n} \mathrm{H}+\underset{\mathrm{HO}-\left[\left(\mathrm{Si}_{2} \mathrm{O}\right)_{n-}\right.}{\mathrm{Al}\left(\mathrm{OR}^{\prime \prime}\right)_{3}} \underset{x}{\left.\mathrm{Al}\left(\mathrm{O} R^{\prime}\right) \mathrm{O}\right]} \underset{x}{R}
$$


Vulcanizable elastomers having good physical properties have been reported.

A contributed paper by D. L. Alletson, A. G. Davies and B. N. Figgis (University College, London) described work on the dialkyl tin oxides, indicating the existence of tin analogues of both the ring and chain siloxanes. Four-membered rings are believed to occur among the stannoxanes.

Another well-known group of inorganic polymers are the phosphonitrilic compounds, of which the most familiar is the chloride $\left(\mathrm{PNCl}_{2}\right)_{n}$, sometimes referred to as 'inorganic rubber'. In his lecture, Dr. C. P. Haber (U.S. Naval Ordnance Laboratory, California) summarized recent work, including several new general methods of synthesis. The usual procedure for the chloride involves reaction of ammonium chloride with phosphorus pentachloride $\left(\mathrm{PCl}_{5}\right)$, and can be modified to give ( $\left.\mathrm{PN} R_{2}\right)_{n}$ by replacing $\mathrm{PCl}_{5}$ by $\mathrm{PCl}_{3} R_{\mathrm{a}}$. This method always gives cyclic products; in the case of the chloride these are readily polymerized by heating. The chain polymer $\left(\mathrm{PN} R_{2}\right)_{n}$ $(R=\mathrm{Me}$, Et, $\mathrm{Ph})$ cannot, however, be obtained in this way, as the ring does not open on heating. Reaction of $\mathrm{PCl} R_{2}$ with sodium azide leads, via $R_{2} \mathrm{PN}_{3}$, to chain polymer. Substitution reactions can also be used to replace chlorine by other groups. By these various techniques, a considerable range of both cyclic and polymeric phosphonitrilic compounds have now been made.

One of the most interesting problems associated with the phosphonitrilic compounds concerns their electronic constitution, that is, the nature of the $\mathrm{P}-\mathrm{N}$ bond. In a contributed paper, N. L. Paddock (Manchester) reviewed this problem in the light of recent thermochemical and spectroscopic measurements and studies of base strength. There is no doubt that delocalized bonds are formed, both in rings and in the chain, by overlap of $p$ orbitals of $\mathrm{N}$ with $d$ orbitals of $\mathrm{P}$. It is possible, on this basis, to understand why the stability of a PN ring is very much less dependent on its size than is that of a hydrocarbon $(\mathrm{CH})_{n}$. This problem was also referred to by Prof. A. B. Burg (Southern California) in his lecture. Discussing the polymerizability of th? 6-membered ring $\left(P X_{2} \mathrm{~N}\right)_{3}$, Burg sought for factors tending to increase the size of the angle PNP, and on this basis deduced as the order of increasing polymerizability: $X=\mathrm{N} R_{2}<\mathrm{Me}$ or $\mathrm{Ph}<\mathrm{Cl}<\mathrm{F}$ or $\mathrm{CF}_{3}$.

Turning to $\mathrm{BN}$ polymers, Burg reported that the chain polymer $\left(\mathrm{Me}_{2} \mathrm{~N} . \mathrm{BH}_{2}\right)_{n}$ is unstable at room temperature, but the 6-membered ring $(n=3)$ is unchanged by heating at $300^{\circ} \mathrm{C}$. The structure of this compound has been determined (by Lipscomb) and found to be of cyclohexane chair form, with ring angles of $113-114^{\circ}$. The corresponding phosphinoborine $\left(\mathrm{M}_{2} \mathrm{PBH}_{2}\right)_{3}$ is similar, with ring angles $118^{\circ}$ (P) and $112^{\circ}(\mathrm{B})$.

BN polymers were further discussed in the lecture by Prof. A. W. Laubengayer (Cornell) who represented three stages arising by progressive removal of $R X$ from a co-ordination compound $\mathrm{I}$ of $R_{\mathrm{3}} \mathrm{N}$ and $\mathrm{B} \bar{X}_{3}$ :

$$
\left.\underset{\mathrm{I}}{R_{3} \mathrm{~N}} \rightarrow \underset{\mathrm{II}}{\mathrm{B} X_{3}} \rightarrow \underset{\mathrm{III}}{\left.\mathrm{B} X_{2}\right)_{n}} \rightarrow \underset{\mathrm{IV}}{\left(R_{2} \mathrm{~N}\right.} \rightarrow \underset{n}{(R \mathrm{~N}}-\mathrm{BX}\right)_{n} \rightarrow \underset{n}{(\mathrm{BN})_{n}}
$$

In series II, both $\mathrm{B}$ and $\mathrm{N}$ are approximately tetrahedral, but there is charge alternation in the ring or chain. Series III has as its parent member borazole $(\mathrm{NH}-\mathrm{BH})_{3}$, which possesses a plane aromatic ring and closely resembles benzene. The corresponding chain is unknown: on pyrolysis borazole gives a variety of products, among which have been identified analogues of naphthalene and diphenyl. Boron nitride (IV) forms a layer structure very similar to graphite, but with $\mathrm{B}^{-}$and $\mathrm{N}^{+}$alternating in adjacent layers. Aluminium-nitrogen polymers have been less studied, and there is no evidence for a borazole analogue. $(\mathrm{Me} \mathrm{N} . \mathrm{AlCl})_{n}$ is a very stable, insoluble material, possibly:

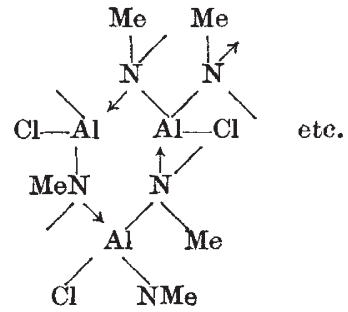

Several contributed papers also dealt with BN polymers. W. Gerrard and E. F. Mooney (Northern Polytechnic, London) reported that borazole ring formation could be prevented by bulky substituents (III, $R=\mathrm{P}$ or Bu, $X=\mathrm{Ph}$ ). J. Dewing (Imperial Chemical Industries, Billingham) reported the polymerization of $\mathrm{Me}_{2} \mathrm{~N} \cdot \mathrm{BH}_{2}$ by heating at $150^{\circ} \mathrm{C}$. and 3,000 atm., to an amorphous, infusible, insoluble polymer, which slowly reverted to a cyclic dimer under ambient conditions.

The two remaining lectures, by Prof. J. C. Bailar (Illinois) and Prof. O. Schmitz-Dumont (Bonn), both dealt with co-ordination polymers. The underlying principles are straightforward, though their application to produce useful polymers has not yet been successful. The most useful technique involves polymerization by co-ordination, and requires the use of a bi- or poly-functional ligand. A very simple example is

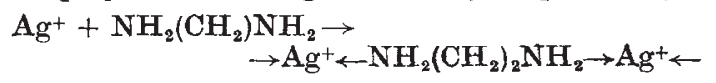

A metal of higher co-ordination number can form chelate rings; use of bis-diketones then leads tc very stable polymers such as

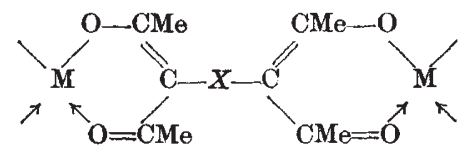

where $X$ is any linking unit such as $\left(\mathrm{CH}_{2}\right)_{n}$ or $\mathrm{C}_{6} \mathrm{H}_{4}$. A variation on this procedure involves linking together, for example, by polycondensation, units which are already co-ordinated, that is, making the $X$ bridges. It will be seen that the 'inorganic' content of such a structure is extremely small.

In this review of the symposium, no attempt has been made to mention all the convributors or all the topics discussed. It will be clear that the emphasis was on the preparation of polymers. The symposium offered a timely opportunity to take stock of the present position, and should lead to some reorientation of future effort. While there is clearly much synthetic work still to be done, increasing attention should now be given to reaction mechanisms and energetics, and to the physical study of the products. Prof. C. C. Addison and his colleagues on the organizing committee are to be congratulated on a most successful venture, which may well exercise an appreciable influence on the development of the subject.
G. GEE 